\title{
The Study on Recommissioning of a Laboratory Building in the Industrial Park
}

\author{
Shaoyuan Jiang \\ Graduate student, Suzhou University of Science and \\ Technology \\ Suzhou, China \\ e-mail:494193026@qq.com
}

\author{
Chenggang Liu \\ Professor, Suzhou University of Science and \\ Technology \\ Suzhou, China \\ e-mail:cliu1977@163.com \\ * Corresponding author
}

\author{
Rundong Liu \\ School of Environmental Science and Engineering \\ Suzhou University of Science and Technology \\ Suzhou, China \\ e-mail:549269992@qq.com
}

\begin{abstract}
The laboratory buildings are not main part of industrial buildings in the developing countries like China. However, the energy intensity of those buildings is on the top of industrial buildings because of requirement of temperature and relative humidity control. As an example in this paper, the recommissioning of a laboratory building in the industrial park located in the region of hot and humid climate is introduced, including in the issues of controls, optimization of temperature and relative humidity control and savings analysis.
\end{abstract}

Keywords-Recommissioning; Industrial Park; Energy Saving

\section{Laboratory Building;}

\section{RECOMMISSIONING AND FACILITY INTRODUCTION}

Recommissioning technology is widely used for recommissioning service, in order to improve the energy efficiency of existing buildings because of inadequate understanding of the problems and insufficient engineering knowledge by some facility operations staff [1].

There are several benefits from recommissioning activates. First, during the recommissioning process, a thorough engineering inspection is conducted and measurements are made. Sustainable engineering solutions based on fundamental engineering principles are developed and implemented [2].

Second, through the recommissioning, the HAVC system can operate more efficiently to meet the building load. Design engineers face uncertainties in building design because they lack knowledge of actual occupancy levels and construction quality. To insure a workable building, HVAC systems are often designed with more capacity than required [3-4]. The HVAC engineers often pay little attention to part-load control and operation. Consequently, working as designed, a system may have poor energy performance. In addition, an excessively large system often creates comfort problems since it may not control well under very low load conditions.
Third, during the recommissioning process, the recommissioning engineers work closely with the building staff to identify operating problems and determine optimal operating strategies. The staff is also heavily involved in the decisions to implement specific recommissioning measures and may actually implement these measures. They gain a higher level of skill and understanding of the engineering principles involved in optimal building operation [5].

Finally, the recommissioning can be a service as an enabling factor for a comprehensive facility overhaul. A comprehensive system overhaul or major system upgrade is often delayed or canceled due to lack of funding. This problem can be resolved if savings from the recommissioning process are used to fund the upgrade project [6-7]. The recommissioning process can have another significant impact on retrofit projects. It reduces the audit and engineering analysis cost since major costeffective measures are normally identified during the recommissioning process. It also decreases the risk of engineering mistakes during retrofits since the commissioning process results in an excellent understanding of the characteristics and operation of the existing systems. Consequently, retrofit costs can be controlled to a minimum [8-10].

The laboratory building recommissioned is a 3-story building with a basement. The total floor area of the building is about $7,800 \mathrm{~m} 2$. The basement has a parking garage. The 1st floor is mainly offices and meeting rooms. The 2 nd floor is a material lab. The 3rd floor has biological labs.

There are 5 air handling units (AHUs) in the building. AHU-1, AHU-2 and AHU-3 are single-duct variable air volume (SDVAV) systems with the reheat terminal boxes and direct digital control (DDC) on the energy management control system (EMSC), serving the building from the 1st through the 3rd floors respectively. AHU-4 is a fresh air handling unit providing the fresh to the AHU-1 
to AHU-3. AHU-5 serving the 3rd floor possessed is a make-up air handling unit with a heating coil only. Both of AHU-4 and AHU-5 were possessed with local pneumatic control. The terminal reheat boxes were possessed with local pneumatic control as well. The chilled water and heating hot water are served by two building pumps in the basement. Both chilled water and hot water pumps have variable frequency drive (VFD) for its speed control. The chilled water and heating hot water is from the water loop of Industrial Zone. There are 14 exhaust fans on the roof of the main part of the building. Twelve of them are used for exhaust in the laboratories on the 3rd floor, and other two are for restrooms exhaust. These AHUs and exhaust fans run 24 hours per day and 7 days per week.

\section{HAVC SYSTEMS HARDWARE AND SOFTWARE CONCERNS}

Major recommissioning activities is included, but not limited in checking all five AHUs, all exhaust fans, and building chilled water and hot water systems; working on the thermostats, reheat control valves and terminal boxes; and performing exhaust measurement and an air balance for the biological labs on the 3rd floor. Also the control sequence for all equipment with DDC control was checked. The major problems found are as below.

1. Chilled water flow meter had a wrong reading, because the ports of high side and low side were dirty. The wrong reading leaded to a high differential pressure setpoint and increased chilled water pump speed.

2. Make up air handling unit (AHU-5) for lab hoods has inlet vanes. The controller for the inlet vanes was not working properly and resulted in the fan works at full capacity. The lab was hot when the make-up air unit was on. To simply solve the problem, the operator shut the unit off for several years. However, it increased energy consumption because of exhausting the conditioned air.

3. Static pressure sensors of AHU-1 need to be calibrated. The measured static pressure was 870 pa with the reading of $642 \mathrm{pa}$ on the EMSC. This result in the fan ran at high speed.

4. Coiling coil of AHU-2 needs to be replaced, since the water side of the coil was restricted and result in discharge air temperature was over $16^{\circ} \mathrm{C}$, which was $2^{\circ} \mathrm{C}$ higher than the design.

5. The hot water control valve of AHU-3 is rusted and allowing water to flow even when the valve is shut. The measured discharge air temperature was $15^{\circ} \mathrm{C}$, instead of $20^{\circ} \mathrm{C}$, by closing the manual valve.

6. Most of thermostats for terminal box control are not working properly. They need to be either calibrated or replaced.

7. There is a hot water bypass valve between the building supply and return pipes, which is allowing a minimum water flow even the pump possesses a VFD. It needs to be closed/removed.

8. Two exhaust fans for lab were needs new belts. The bad belts reduced the capacity of exhaust fans.

9. The 3rd floor needs air balance because the static pressure of several lab rooms is too positive. It is harmful to the building environment.

10. Existing Control Scheme.

(1) Chilled water pumps and control valve control
The pump speed is varied to maintain the DP at its setpoint. The DP setpoint is calculated from the following equation.

$$
\mathrm{DP}_{\mathrm{sp}}=\mathrm{Q}^{2} / 2160
$$

Here $\mathrm{Q}$ is the chilled water flow $(\mathrm{m} 3 / \mathrm{h})$

The examples of the DP setpoint calculated from the equation are list in the Table 1.

TABLE I. BUILDING CHILLED WATER DP RESET SCHEDULE

\begin{tabular}{|c|c|c|}
\hline \multirow{4}{*}{ Building DP } & $\mathrm{Q}\left(\mathrm{m}^{3} / \mathrm{h}\right)$ & $\mathrm{DP}(\mathrm{mH} 2 \mathrm{O})$ \\
\cline { 2 - 3 } Reset Schedule & 60 & 1.7 \\
\cline { 2 - 3 } & 90 & 3.8 \\
\cline { 2 - 3 } & 120 & 6.7 \\
\cline { 2 - 3 } & 150 & 10.4 \\
\cline { 2 - 3 } & 180 & 15.0 \\
\hline
\end{tabular}

The chilled water control valve is modulated to be fully open before the pump is on. Chilled water pump will be on and speed will be increased to maintain the building DP at its setpoint, when loop pressure is not high enough to keep the building DP at its setpoint. Chilled water pump will be on and speed will be increased to maintain the building DP at its setpoint.

(2) Chilled water valve control for AHU-1, 2 and 3

Chilled water valve is modulated to maintain the cold duct temperature at its setpoint of $14^{\circ} \mathrm{C}$ constant value. It will make the interior zone of the building cold during winter. We recommend the cold duct temperature setpoint be reset according to the outside air temperature.

(3) Fan speed control for AHU-1, 2 and 3

Fan speed is controlled to maintain the static pressure at its setpoint and the setpoint is a constant value of $685 \mathrm{pa}$. We recommend the static pressure setpoint be reset according to the outside air temperature.

\section{HAVC SYSTEMS HARDWARE AND SOFTWARE SOLUTION}

1. The ports to the chilled water flow meter are cleaned and the meter is calibrated. The chilled water building DP is reset correctly after the correction ${ }^{[11]}$. The chilled water pump speeds up and slows down to meet the requirement of building cooling load exactly.

2. The controller of make-up air handling unit (AHU-5) is replaced so that the unit can be turned on to stop exhausting the conditioned air so that the indoor air quality was improved and the significant energy saving was achieved.

3. Static pressure sensors of AHU-1 were calibrated.

4. Coiling coil of AHU-2 has been replaced,

5. The hot water control valve of AHU-3 was replaced. The valve does not allow the water flowing through it when commanded shutting off.

6. All of seventy thermostats for terminal box control were checked. It is found that twenty six of them need calibration. There were twenty five thermostats not working at all and needing to be replaced. The number of thermostats for calibration and replacement is list in Table 2. 
TABLE II. THERMOSTATS CALIBRATION/REPLACEMENT

\begin{tabular}{|c|c|c|c|c|}
\hline Floor & 1 st & 2nd & 3rd & Total \\
\hline $\begin{array}{c}\text { Total boxes/ } \\
\text { Thermostat }\end{array}$ & 23 & 26 & 21 & 70 \\
\hline Calibrated & 12 & 8 & 6 & 26 \\
\hline Replaced & 7 & 10 & 8 & 25 \\
\hline
\end{tabular}

7. The hot water bypass valve between the building supply and return pipes was removed after a three-way control valve was installed on the last terminal reheat box from the pump. Now there is no hot water back to the return pipe without used. So that the hot water pump can be slowed down in the most period of the time.

8. Two exhaust fans for lab have new belts so that the capacity of exhaust fans is improved.

9. An air balance on the 3rd floor was performed after the make-up air handling unit was turned on. Before air balance, there was the positive pressure in rooms 302, 307, 312 and 313 because the make-up air flow was larger than the exhaust. The pressure in rooms 305 and 313 was too negative. ${ }^{[12]}$ Table 3 shows the lab pressure data, before and after the air balance. The pressure of $7.5 \mathrm{~Pa}$ between the 3rd floor and the 2nd floor hallway is also recommended.

TABLE III. 3RD FLOOR LAB PRESSURE DATA

\begin{tabular}{|l|l|l|l|l|l|l|}
\hline Room No. & 302 & 305 & 307 & 312 & 313 & 315 \\
\hline $\begin{array}{l}\text { Pre Rcox } \\
\left(\mathrm{mmH}_{2} \mathrm{O}\right)\end{array}$ & 1.2 & -2.8 & 0.89 & 0.0 & 1.0 & -2.1 \\
\hline $\begin{array}{l}\text { Post Recx } \\
\left(\mathrm{mmH}_{2} \mathrm{O}\right)\end{array}$ & -1.0 & -1.2 & -1.5 & -1.5 & -1.3 & -1.4 \\
\hline
\end{tabular}

10. New Control Schemes.

\section{A. Chilled water pump speed control}

The DP setpoint is calculated from the modified equation as below and typical values of the setpoint corresponding to the chilled water flow rate are list in the Table 4 . The new setpoint is reduced by about $18 \%$ than the old DP setpoint, which will save more than $40 \%$ pump power

$$
D P_{s p}=Q^{2} / 2650
$$

TABLE IV. New SetPoint of ChILLED WATER BuILDing DP

\begin{tabular}{|c|l|l|}
\hline & $\mathrm{Q}\left(\mathrm{m}^{3} / \mathrm{h}\right)$ & $\mathrm{DP}(\mathrm{mH} 2 \mathrm{O})$ \\
\cline { 2 - 3 } Chilled water & 60 & 1.4 \\
\cline { 2 - 3 } DP Setpoint & 90 & 3.1 \\
\cline { 2 - 3 } & 120 & 5.4 \\
\cline { 2 - 3 } & 150 & 8.5 \\
\cline { 2 - 3 } & 180 & 12.2 \\
\hline
\end{tabular}

B. Chilled water valve control for $A H U-1,2$ and 3

The chilled water valve is controlled to maintain cold duct temperature at its setpoint. Cold duct temperature setpoint is reset according to outside air temperature. instead of $14^{\circ} \mathrm{C}$ constant value any more. See Table 5. The new setpoint is varied from $14^{\circ} \mathrm{C}$ to $17^{\circ} \mathrm{C}$ corresponding to the outside air temperature of $30^{\circ} \mathrm{C}$ to $10^{\circ} \mathrm{C}$. When outside air temperature is greater $30^{\circ} \mathrm{C}$, the setpoint maintains at $14^{\circ} \mathrm{C}$. When outside air temperature is below $10^{\circ} \mathrm{C}$, the setpoint keeps $17^{\circ} \mathrm{C}$. The cooling energy saving can be achieved from the new cold duct temperature reset.

TABLE V. New Reset Schedule of Cold Duct Temperature

\begin{tabular}{|c|c|c|}
\hline \multirow{4}{*}{$\begin{array}{c}\text { New Reset } \\
\text { Schedule of Cold }\end{array}$} & $\begin{array}{c}\text { OA Temp } \\
\left({ }^{\circ} \mathrm{C}\right)\end{array}$ & $\begin{array}{c}\text { Tcd setpoint } \\
\left({ }^{\circ} \mathrm{C}\right)\end{array}$ \\
\cline { 2 - 3 } Duct Temperature & 10 & 17 \\
\cline { 2 - 3 } & 15 & 16 \\
\cline { 2 - 3 } & 20 & 15 \\
\cline { 2 - 3 } & 30 & 14 \\
\hline
\end{tabular}

C. Fan speed control for AHU-1, 2 and 3

The fan speed is controlled to maintain the static pressure at its setpoint. The static pressure setpoint is set according to outside air temperature. Instead of a constant value of $685 \mathrm{~Pa}$ any more. See Table 6 . The static pressure setpoint of AHU-1 varies from $550 \mathrm{~Pa}$ to $675 \mathrm{~Pa}$ corresponding to the outside air temperature of $10^{\circ} \mathrm{C}$ to $30^{\circ} \mathrm{C}$. The static pressure setpoint of $\mathrm{AHU}-3$ varies from $530 \mathrm{~Pa}$ to $670 \mathrm{~Pa}$ corresponding to the outside air temperature of $10^{\circ} \mathrm{C}$ to $30^{\circ} \mathrm{C}$. The static pressure setpoint of AHU-3 varies from $565 \mathrm{~Pa}$ to $685 \mathrm{~Pa}$ corresponding to the outside air temperature of $10^{\circ} \mathrm{C}$ to $30^{\circ} \mathrm{C}$. The average low side of the setpoint is reduced by $136 \mathrm{~Pa}$ which is about $20 \%$ reduction.

TABlE VI. New Reset Schedule of the Static Pressure

\begin{tabular}{|c|c|r|r|r|}
\hline \multirow{3}{*}{$\begin{array}{c}\text { New Reset } \\
\text { Schedule }\end{array}$} & $\begin{array}{c}\text { OATemp } \\
\left({ }^{\circ} \mathrm{C}\right)\end{array}$ & \multicolumn{3}{|c|}{$\begin{array}{c}\text { Static Pressure setpoint } \\
(\mathrm{Pa})\end{array}$} \\
\cline { 3 - 5 } of the & 10 & AHU-1 & AHU-2 & AHU-3 \\
\cline { 2 - 5 } $\begin{array}{c}\text { Static } \\
\text { Pressure }\end{array}$ & 15 & 550 & 530 & 565 \\
\cline { 2 - 5 } & 20 & 630 & 575 & 600 \\
\cline { 2 - 5 } & 30 & 675 & 670 & 635 \\
\hline
\end{tabular}

\section{SAVING ANALYSIS}

After the implementation of recommissioning measures, energy consumption data for chilled water, heating hot water, and electricity is collected and compared with associated annual data before recommissioning shown in Fig. 1 through Fig. 3. In those figures, data shown as " $X$ " is the energy consumption before the recommissioning and data shown as “ $\square$ ” is the energy consumption after recommissioning.

From Fig. 1, chilled water consumption is reduced by an average of about $200 \mathrm{kw}$ or $25 \%$,

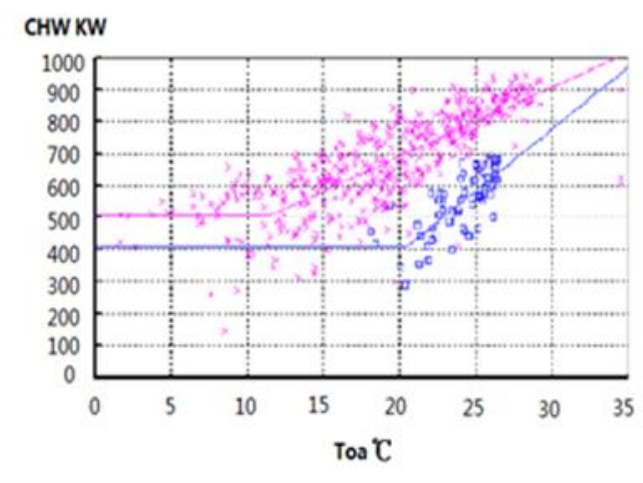

Figure 1. Chilled Water Consumption Data 
According to Fig. 2 and Fig. 3, hot water consumption reduced by an average of about $150 \mathrm{kw}$ or $30 \%$ and electricity consumption reduced by an average of about 70 $\mathrm{kw}$ or $20 \%$.

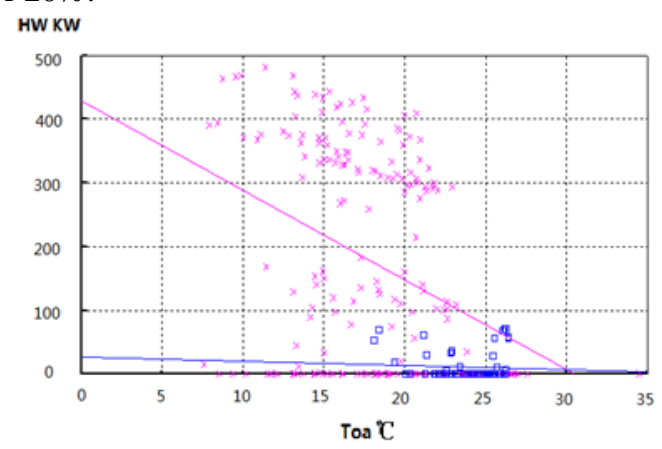

Figure 2. Hot Water Consumption Data

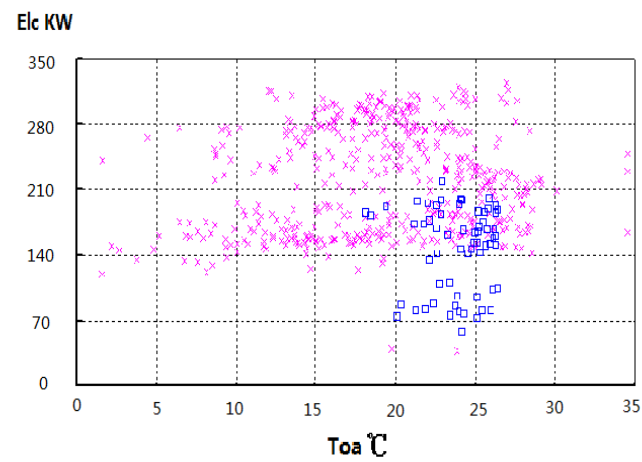

Figure 3. Electricity Consumption Data

The savings above are the result of commissioning activities such as new control scheme, hardware maintenance, replacing bad thermostats. performing air balance and turning on the make-up air handling unit.

\section{SUMMARY OF RECOMMENDATION}

Heating coil of AHU-2 needs to be replaced, because it has loss heating capacity. When the outside is extremely cold, the heating coil could not provide enough heat.

The existing electricity meter is installed, in order to measure all building electricity consumption instead of HVAC equipment. The meter to measure HVAC equipment needs electricity consumption needs to be installed so that it can be separated from lighting and office equipment and plugs. The air duct of each air handling unit needs to be cleaned because of falling dirty dust from the diffusers when the supply air fan runs at high speed.
All exhaust fans on the roof need to be checked in mechanic, because the flow rate for most exhaust fans doesn't match design.

The recommissioning activities of a laboratory building in the industrial park located in the region of hot and humid climate is introduced and discussed including in the issues of controls, optimization of temperature and relative humidity control, HVAC hardware problems and savings analysis. The significant energy savings can be achieved from recommissioning.

\section{REFERENCES}

[1] Nakahara N. Study and practice on HVAC system commissioning [C] Proceeding s o f the 2003 - 4th International Symposium on Heating, Ventilating and Air Conditioning. Beijing, 2003 :44 61

[2] Steve Doty.Simplifying the commissioning process energy engineering [J]. ProQuest Science Journal.2007,104(2):25-45

[3] Guo Xinjian. Analysis of Energy-Saving Hydraulic System Design Parameters on Bulldozer[A]. Proceedings of the 2009 International Conference on Advances in Construction Machinery and Vehicle Engineering. 2009

[4] Nakahara N , Xu Guo hai . Study on ongoing commissioning process for actual HVAC system of an existing building, part 1: on-going commissioning outline and effort for HVAC optimal o peration [C] Proceedings of SHASE Academic Lecture Meeting. Japan , 2004:807 810

[5] Liu Ming sheng, Claridge D E, Turner W D.Continuous commissioning of building energy systems [ J] . Journal of Solar Energy Engineering, 2003, 125(8):275 281

[6] Robert K. Commissioning HVAC contro ls system[ J] . ASHRAE, 2001(12):27 30

[7] Zheng Ming jie , Yasutomo T, Nakahara N. Fault simulation and commissioning of $\mathrm{H}$ VAC system using HVACSIM $+[\mathrm{C}]$ Pro ceedings of the 2003 - 4th Inter national Symposium on Heating, Ventilating and Air Conditioning. Beijing, $2003: 11291136$

[8] Wang Fulin, Yoshida H. Experiment study on continuous commissioning a real VAV system [ C] Proceedings of the 2003 4th International Symposium on Heating, Ventilating and Air Conditioning . Beijing, 2003:959 966

[9] ZHANG Wei-wei.Analyses of the related questions of the chemical laboratory ventilation design $[\mathrm{J}]$ Building Energy\& Environment, 2010 29( 1) : 97-100.

[10] Roth K W, Westphalen D, Brodrick J. Saving energy with building commissioning $[\mathrm{J}]$ ASHRAE Journal, 2003, 45( 11) : 65-66.

[11] C.G. Liu, Optimization and H.L. Bruner, Analysis of HAVC System for a Multi-Functional Institutional Building, Advanced Building Materials, Part 4, Trans Tech Publications, 2011: 3144 3149.

[12] C.G. Liu, G.H. Wei, H.L. Bruner, The Optimization of Temperature and Relative Humidity Control in Cushing Library, Advanced Building Materials, Part 4, Trans Tech Publications, 2011: 31393143 . 